\title{
HOW DO ARTISTS INNOVATE ON SCENE? UNDERSTAND THE IMPLEMENTATION OF ARTISTIC INNOVATION THROUGH THREE CANADIAN MUSIC FESTIVALS.
}

\author{
Paulin Gohoungodji, Laval University, Quebec City, Quebec, Canada
}

dx.doi.org/10.18374/IJSM-20-1.7

\begin{abstract}
Implementing artistic innovation in music festivals is complex but also risky. Indeed, any failure in its realization can have a negative impact on the success of the festivals. In this study, the objective is to understand how music festival stakeholders conceive of artistic innovation to provide the tools and best practices to make it more successful. Based on a qualitative research, the analysis revealed that stakeholders in the achievement of artistic innovation in music festivals can be human or non-human actors. Secondly, regarding strategies for the implementation of artistic innovation, it appears that the realization of artistic innovation can take place in three forms. It can be the result of a combination of activities between several stakeholders in the form of collaboration. It can also arise from a controversial situation where several forces are in contradiction. In this case, it is from a situation of interaction that artistic innovation arises. Finally, artistic innovation can be only the result of an individual action of a given stakeholder. In this instance, it is the result of an individual activity carried out by a single actor.
\end{abstract}

Keywords: Artistic innovation - Music festivals- Implementation - Strategies - Stakeholders 